\title{
UM ESTUDO DAS RELAÇÕES INTERPESSOAIS EM FAMÍLIAS COM FARMACODEPENDENTES
}

\author{
Jair Lourenço Silva* \\ Rosa Maria S. Macedo \\ Alice Moreira Derntl" \\ Nancy Benedita Berrueso Bergami ${ }^{\infty}$
}

\begin{abstract}
RESUMO. Este estudo tem como objetivo evidenciar as implicações dos padrões de humor na manutenção do ciclo da drogadicção nos sistemas familiares com dependentes químicos, tendo como pressupostos as correlações entre drogadicção e transtornos de humor. Consideramos importante investigar como os padrões de depressão e mania afetam e são afetados, recursivamente, pelo sistema familiar com membro adicto. Apresentamos um estudo de caso de terapia familiar estrutural e estratégica de uma família com um membro adicto. Analisamos os resultados deste estudo focando a atenção nos dados que estes modelos de terapia possibilitam e nas categorias descritivas de padrões de humor criadas por Stierlin, Weber, Schmidt e Simon (1986), que trabalharam com famílias com transtornos de humor. Esta pesquisa colaborou para ampliar nossa visão sobre os diversos fatores que podem influenciar na manutenção da dependência de drogas nos sistemas familiares com membro adicto.
\end{abstract}

Palavras-chave: relacionamento familiar, drogadicção, transtorno de humor.

\section{A STUDY OF INTER-PERSONAL RELATIONSHIPS IN FAMILIES WITH A DRUG ADDICTED}

\begin{abstract}
This study has as main objective to emphasize the implications of mood patterns in the maintenance of the drug addiction cycle, in family systems with chemical dependents, assuming that there is a correlation between drug addiction and mood disorders or perturbations. We considered important to investigate how depression and mania patterns, recursively, affect and are affected by the family system with a chemical-dependent member. We presented a case study of structural and strategic family therapy, in a family with an addicted member. We analyzed the results of the study, by focusing on both, the data that emerged from those models of therapy, and on descriptive categories related to mood patterns created by Stierlin, Weber, Schmidt and Simon (1986), who worked with families presenting mood disorders. The study helped to enlarge our views on the several factors that can influence the maintenance of drug dependence in family systems with addicted members.
\end{abstract}

Key words: Family relationship, drug addiction, mood disorders.

\section{UN ESTUDIO DE LAS RELACIONES INTERPERSONALES EN FAMILIAS CON FARMACODEPENDIENTES}

\begin{abstract}
RESUMEN. Este estudio tiene como objetivo evidenciar las implicaciones de los modelos de humor en la manutención del ciclo de la drogadicción en los sistemas familiares con adictos químicos, teniendo como postulados las correlaciones entre drogadicción y trastornos de humor. Consideramos importante investigar como los modelos de depresión y manía afectan y son afectados, recursivamente, por el sistema familiar con miembro adicto. Presentamos un estudio de caso de terapia familiar estructural y estratégica de una familia con un miembro adicto. Analizamos los resultados de este estudio fijando atención en los datos que estos modelos de terapia posibilitan y en las categorías descriptivas de modelos de humor criadas por Stierlin, Weber, Schmidt y Simon (1986), que trabajaron con familias con trastornos de humor. Esta investigación colaboró para ampliar nuestra visión sobre los diversos factores que pueden influenciar en la manutención de la adicción de drogas en los sistemas familiares con miembro adicto.

Palabras-clave: relación familiar, drogadicción, trastorno de humor.

\footnotetext{
* Mestre em Psicologia Clínica, Médico Psiquiatra do Hospital das Clínicas da Faculdade de Medicina da USP.

\# Doutora. Professora Titular do Departamento de Pós-Graduação da PUC- SP.

II Doutora. Professora do Departamento de Práticas em Saúde Pública da Faculdade de Saúde Pública da Universidade de São Paulo.

x Mestre em Psicologia. Professora do Departamento de Psicologia da Universidade Estadual de Maringá-PR.
} 
Neste artigo nos propomos a compreender o ciclo da drogadicção no âmbito familiar sob o olhar da teoria sistêmica, particularmente utilizando os modelos de terapia familiar sistêmica estrutural de Minuchin e Fishman (1990) e a estratégica de Haley (1979), com o objetivo de evidenciar as implicações dos padrões de humor $^{1}$ na manutenção do ciclo da drogadicção nos sistemas familiares com dependentes químicos.

Tomamos como referência alguns estudos que relatam as co-morbidades de transtorno de humor em dependentes químicos: Silveira (1997), em sua pesquisa com estudantes de medicina e farmacodependentes, encontrou entre estes estudantes uma freqüência de $23 \%$ de depressão e entre os farmacodependentes uma freqüência de $32 \%$ para o mesmo transtorno. Bergeret e Leblanc (1991) consideravam que as pesquisas epidemiológicas da década de 1990 mostravam que a maioria dos toxicômanos encontrados era constituída por indivíduos com personalidade depressiva, e Kaplan e Sadock (1997) descrevem que os sintomas depressivos são muito freqüentes em dependentes químicos: cerca de 30 a $50 \%$ dos abusadores ou dependentes de opióides reúnem critérios para transtorno depressivo maior em algum momento de suas vidas. Lourenço e Cordás (2006) também apontam a correlação entre essas duas patologias, ao referirem que na adolescência é muito importante o clínico estar atento ao diagnóstico diferencial, assim como à co-morbidade, entre transtorno de humor e drogadicção, pois tanto os sintomas depressivos como os maníacos podem fragilizar o jovem para a drogadição. Estudos como estes ratificam a importância de se considerar a comorbidade de transtorno de humor no indivíduo dependente químico para a prevenção e tratamento da dependência de drogas.

$\mathrm{Na}$ prática clínica com dependência química vem se consolidando a importância do olhar sistêmico, que considera tanto os aspectos individuais quanto os sociofamiliares para a compreensão dos fenômenos complexos, como a drogadicção. Macedo (1996) chama a atenção para a importância da abordagem sistêmica no âmbito sociofamiliar no tocante à compreensão dos fenômenos complexos, retirando o foco do paciente identificado (P.I. - o paciente que expressa o sintoma no sistema familiar), que em nosso

1 Tomamos como referência para nosso estudo o conceito de espectro de doença bipolar referido por Kaplan e Sadock (1997) como a existência de numerosas formas de transição entre estados depressivos e maníacos. Assim os termos, mania, depressão, transtornos do humor, transtorno afetivo, e padrões de humor são citados com referência à mesma patologia. estudo seria o dependente químico, e colocando-o nas relações familiares. Buscamos assim compreender o sintoma/doença a partir das inter-relações familiares, como o sintoma interfere no sistema familiar e é por ele afetado.

Em face dessas considerações, interessou-nos investigar como os padrões de depressão se expressam no âmbito familiar das famílias com dependente químico, ou seja, como os padrões de transtorno de humor do componente com drogadicção afetam e são afetados pelo sistema familiar recursivamente, procurando evidenciar as implicações desses padrões de humor na manutenção do ciclo da drogadicção nos sistemas familiares com dependentes químicos, o que pode colaborar para a prevenção e o tratamento da drogadicção.

Com este propósito, usamos a terapia familiar breve, estrutural e estratégica proposta por Piszezman (1999), que utiliza conjuntamente as técnicas de terapia familiar estrutural de Minuchin e Fishman (1990) e a estratégica de Haley (1979). Piszezman (1999) cita Bodin, que compartilha da visão interacional, sem distinguir entre a abordagem estratégica e estrutural. Stanton e Todd. (1990), importantes pesquisadores, com estudos clássicos sobre famílias com membros dependentes químicos, também apontam a importância da integração dessas duas abordagens de terapia familiar. Apesar de esses dois modelos de terapia familiar apresentarem diferenças de enfoque sobre a família, podem ser complementares, e sob o ponto de vista epistemológico, são compatíveis, pois ambos são sistêmicos e com o enfoque ecológico descrito por Hoffman (1987). Da técnica estrutural, procuramos utilizar principalmente a construção do mapa familiar, analisando as fronteiras, subsistemas, regras, limites, coalizões e alianças, o que nos permite uma ampla visão do funcionamento e da organização estrutural da família. Com a abordagem estratégica avaliamos a hierarquia familiar, triangulações, sobretudo, a disputa dos membros familiares pelo poder e o foco centrado no problema apresentado pela família. A terapia familiar breve proposta por Piszezman (1999), permitenos resultados efetivos em curto espaço de tempo e constitui-se de dez sessões realizadas semanalmente, com duração de aproximadamente dois meses e meio.

Uma vez investigadas tais características da família, segundo Minuchin (1995), ser-nos-á possível compreender o sistema familiar e, junto com os membros da família, levantar hipóteses de funcionamento e detectar padrões disfuncionais; e ao construir junto com o sistema familiar o mapa 
familiar, poderemos formular hipóteses sobre a família e determinar os objetivos terapêuticos.

Após a descrição dessas características, passamos para a segunda parte da pesquisa: compreender como os transtornos de humor do indivíduo drogadicto se manifestam no âmbito familiar e quais suas implicações na manutenção do ciclo da drogadicção. Para isso utilizamos o estudo de Stierlin, Weber, Schmidt e Simon (1986), pesquisadores da Universidade de Heidelberg, que, tendo estudado famílias com transtorno de humor, elaboraram categorias descritivas dos padrões de relação comunicacional e afetivos destes sistemas familiares, sendo elas: construção e negociação da realidade relacional, sistemas de valores e ideologias, complementaridades familiares restritivas, delegado de ligação e pares polarizados, logo adiante detalhados.

A complementaridade familiar, definida por Elkaïm (1998), acontece quando os cônjuges assumem características opostas (polarizadas), um complementando o outro, como num bom trabalho em equipe. Para Stierlin e cols. (1986), a complementaridade pode ser em alguns casos restritiva, ou seja, um complementaridade disfuncional, à medida que um restringe o outro, impossibilitando-o em sua diferenciação e autonomia. $\mathrm{O}$ termo delegado de ligação é descrito por Stierlin e cols. (1986) como um comportamento influenciado por lealdade e ou aliança de um membro do sistema filial em relação a uma figura parental do sistema familiar. Stierlin e cols. (1986) descreveram, a partir de seu estudo com família com transtorno de humor, os termos par ordenado e par desordenado, respectivamente, como a figura parental que tende ao pólo de depressão e a que tende ao pólo de mania.

A utilização dessas categorias descritivas dos padrões afetivos apresentadas pelos mencionados pesquisadores da Universidade de Heidelgerg (1986) para analisar os padrões relacionais da família com dependente químico por nós estudada se justifica pelo fato de que já é sobejamente conhecida na literatura a co-morbidade entre adicção e transtorno de humor (principalmente depressão), como já citamos anteriormente. $\mathrm{O}$ drogadicto geralmente apresenta uma depressão mascarada pela dependência de drogas, e quando sob os efeitos da cocaína ou do crack, pode manifestar sintomas maniformes. A sutileza da descrição desses padrões relacionais das famílias com transtorno de humor apresentados por Stierlin e cols. (1986) deu-nos condições de ampliar nossa visão sobre estes sistemas familiares com drogadicção.
Em um estudo com "famílias adictas", Lourenço (2001) refere que para a elucidação desta terminologia é preciso reconhecer as "famílias adictas". O autor as descreve como aquelas que apresentam um funcionamento pautado pelo lema "ter para ser", o que, na verdade, é um reflexo do modus operandi da sociedade contemporânea capitalista, altamente consumista, em que a adicção e a necessidade de obter algo para se sentir pertencente à comunidade e manter o status quo promovido pela mídia, são sentidas geralmente como primeira necessidade pelos indivíduos, suas famílias e, por fim, pela sociedade.

Particularmente, neste artigo apresentamos uma família adicta na fase de aquisição do ciclo vital da família descrita por Bergami e Berthoud (1997). As autoras definem essa fase como a primeira do ciclo vital familiar, quando as preocupações do novo casal giram em torno da chegada dos primeiros filhos indo até antes do início da adolescência destes. A demanda do casal nessa fase do ciclo vital está focada em aquisições de bens materiais, emocionais e psicológicos que dêem comodidade e estabilidade para o sistema familiar receber de forma adequada os primeiros filhos. Sabemos que na sociedade capitalista ocidental a passagem por essa fase do ciclo vital é uma tarefa de difícil realização por parte dessas novas famílias e que esse quadro se torna dramático quando nos deparamos com sistemas familiares adictos.

No desenvolvimento desta pesquisa a família em terapia e o terapeuta trabalharam juntos para definir o que seria importante para o sistema terapêutico. Realizou-se um estudo que, em profundidade, leva tempo, esforço e comprometimento de ambas as partes, até que a família, através de sua linguagem, possa descrever suas experiências e necessidades ao terapeuta investigador e este possa aprender com ela a decodificar sua linguagem e reais necessidades, para poder intervir de forma adequada.

A relevância deste estudo está na dificuldade descrita pelos clínicos em separar o que é pertinente à dependência química e o que é da co-morbidade ou traços de sintomas relacionados com transtorno de humor. Acreditamos que a investigação de como esses padrões de humor ocorrem nas famílias com dependência química servirá para melhor compreender o funcionamento familiar, assim como para nortear o trabalho terapêutico com essas família.

A proposta deste artigo é apresentar um estudo de caso, com o objetivo de evidenciar as implicações dos padrões de humor na manutenção do ciclo da drogadicção em um sistema familiar com um membro dependente químico. 


\section{MÉTODO}

O trabalho que realizamos para atingir o objetivo proposto pode ser caracterizado como uma pesquisa qualitativo-interpretativa fundamentada no referencial teórico sistêmico, tendo como pressuposto a implicação dos padrões de humor do indivíduo dependente químico e a recursividade desses padrões dentro de seu sistema familiar.

A pesquisa clínica foi o método adotado para nortear este trabalho. Giami (1989) define pesquisa clínica como aquela em que o pesquisador tem um duplo papel: conduzir a situação terapêutica sem perder de vista a finalidade da pesquisa. No entanto, do ponto de vista ético e científico, não é permitido ao pesquisador-terapeuta levantar questões específicas da pesquisa em detrimento das questões trazidas pelo cliente (família), objetivo primeiro da terapia. Daí a importância do auto-escrutínio do pesquisadorterapeuta, que trabalhará com o material em momentos distintos, olhando-o como dados após a transcrição das sessões. É fundamental na realização desse trabalho que o pesquisador seja flexível o suficiente para questionar e mudar seus métodos e ações diante das demandas do sistema familiar que vão surgindo ao longo da pesquisa.

\section{Participante da pesquisa}

A pesquisa enfocou uma família com um membro dependente químico, na fase de aquisição do ciclo vital familiar, em conformidade com as características estabelecidas por Bergami e Berthoud (1997). A família era pertencente à classe média da cidade de São Paulo e tinha um membro diagnosticado como portador de dependência de drogas (cocaína ou crack), de acordo com o critério diagnóstico DSM-IV para Transtornos Relacionados às Substâncias.

\section{Instrumentos}

Utilizou-se terapia familiar breve, com 10 sessões, de acordo com o modelo proposto por Piszezman (1999), já descrito acima.

\section{Genograma}

Este instrumento, construído junto com a família durante os encontros da terapia familiar, é de grande valia para o conhecimento do sistema familiar, pois nos dá a possibilidade de visualizar todo o sistema familiar nuclear e a família extensa, permitindo-nos uma compreensão mais profunda do desenvolvimento da família diante do problema - ciclo da drogadicção, como veremos a seguir na análise das informações colhidas a partir deste recurso. Utilizamos os símbolos do genograma segundo Cerveny (1994).

\section{Mapa estrutural}

De acordo com Minuchin (1992), o mapa é um esquema organizacional. Funciona como um mapa de território estático, porém nos dá a possibilidade de visualizar o campo de ação da família de forma mais simplificada e imediata, já que o sistema familiar é dinâmico e vive em constantes transformações. Com esse recurso, o terapeuta pode mapear as áreas (subsistemas familiares) disfuncionais, o tipo de fronteira da família e o contexto social no qual ela está inserida.

\section{Procedimentos}

A família em estudo foi convidada a participar desta pesquisa em uma instituição especializada em tratamento de dependência química, obedecendo-se aos critérios éticos estabelecidos para as pesquisas que envolvem seres humanos, descritos na Resolução $\mathrm{N}^{\circ}$ 196, de 10 de outubro de 1996 (Prefeitura do Município de São Paulo, 2004).

A família apresentada foi chamada por nós de família Flores e faz parte de uma pesquisa maior ${ }^{2}$, com uma amostra de quatro famílias nas diferentes fases do ciclo vital familiar: aquisição, adolescência, madura e última, de acordo com Cerveny e Berthoud (1997).

Trabalhamos em sessões de terapia familar, com encontros semanais de uma hora e meia. Participaram dos encontros terapêuticos a família nuclear e a família extensa.

O genograma e o mapa estrutural foram construídos durante o processo terapêutico e junto com a família. As informações foram anotadas e transcritas.

\section{Análise dos dados}

Para a análise dos dados foram primeiramente considerados os conceitos utilizados e enfocados nos modelos de terapia estrutural e estratégica, já descritos anteriormente.

Passamos então a analisar novamente as sessões de terapia com a família Flores, com vista às situações que permitissem identificar as categorias definidas por Stierlin e cols. (1986), já descritas, nesse sistema familiar com dependente químico, podendo assim elaborar as conclusões com base nos pressupostos por nós apontados e relacionados ao objetivo desta pesquisa.

\footnotetext{
${ }^{2}$ Lourenço, J.S. (2001).
} 
Os dados e as informações encontrados foram levantados e avaliados de forma qualitativa, dando coerência ao modelo de pesquisa realizado. Construímos quadros-resumos para melhor visualização das análises e posterior conclusão de nosso trabalho.

\section{ESTUDO DE CASO DA FAMÍLIA FLORES}

A família por nós estudada foi atendida em terapia familiar breve (Piszezman, 1999), em dez sessões, desde o início do tratamento do paciente (identificado como Herbert), em uma clínica de recuperação de farmacodependentes, com equipe multi e interdisciplinar, em regime de internação integral (aproximadamente, 30 dias) e depois em regime aberto, de hospital-dia, conforme protocolo de atendimento desta clínica.

Beatriz, a esposa do P.I, foi encaminhada pela assistente social do serviço onde trabalhava. Após apresentar queda em sua produtividade no trabalho, procurou o serviço médico, e a equipe de saúde mental, ao avaliar sua situação conjugal, identificou conflito conjugal relacionado ao uso abusivo de drogas por parte do esposo, Hebert. Beatriz foi orientada a procurar um serviço especializado em farmacodependência para tratamento de seu esposo.

\section{ANÁLISE DAS SESSÕES COM A FAMÍLIA FLORES}

Ao analisarmos o sistema familiar em questão sistema familiar - composto por Beatriz, (25 anos de idade, com curso universitário incompleto, bancária), Hebert (24 anos de idade, universitário, cursando residência em medicina) e dois filhos pequenos - se encontra na fase de aquisição do ciclo vital familiar. De acordo com Cerveny e Berthoud (1997), essa fase é marcada por demandas muito específicas de adquirir, em todos os sentidos: material, emocional e psicológico. De acordo com Carter e McGoldrick (1995), contextualizar a família em seu ciclo vital é de grande valia para entendermos a problemática apresentada, assim como para nos orientar no trabalho com a família, tendo-se em vista as indicações sobre as tarefas sociais e afetivas da família em cada fase.

Beatriz, ao queixar-se freqüentemente de abandono e falta de afeto por parte do esposo, vai relatando, no desenvolver do processo terapêutico, suas decepções em relação ao casamento. Refere que só adquiriu responsabilidades e encargos que antes, quando solteira, não tinha. Vê-se perdida, sem rumo para a vida. "Não sei o que fazer,sou jovem e, ao mesmo tempo, sinto-me uma velha, sem nenhuma perspectiva para minha vida a não ser trabalhar, pagar e cuidar de meus filhos". Refere que se casou cedo para sair da casa dos pais, porque tinha muitos problemas com os irmãos. O irmão acima dela era dependente de drogas e amigo de Hebert, seu marido, a quem ela havia conhecido por meio desse irmão. (Família Flores, Figura 1), verificamos que o

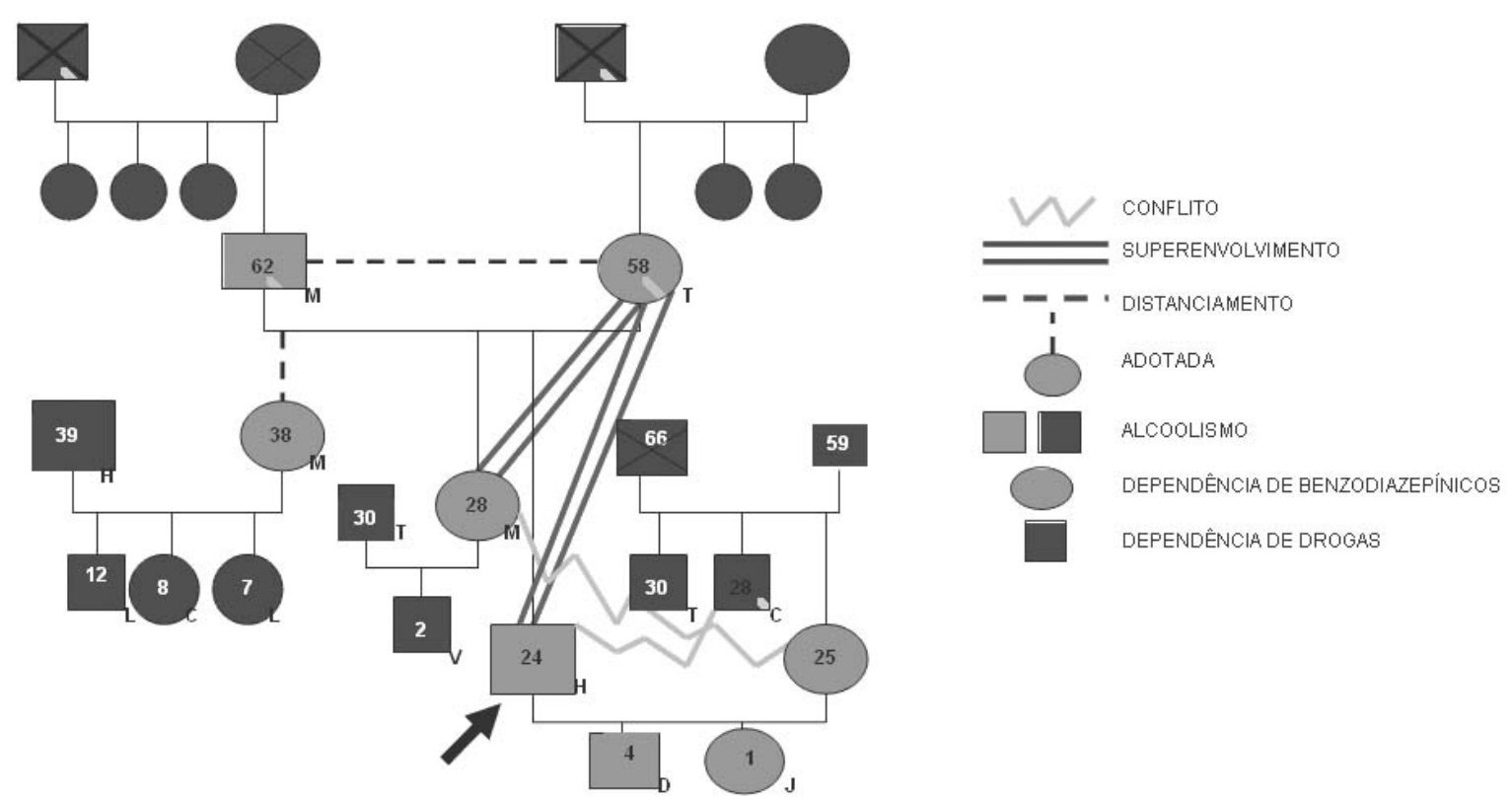

Figura 1. Genograma. Família Flores. 
Descrevia com muito afeto o irmão, a quem ainda ajudava financeiramente. Beatriz era uma mulher muito bonita e dinâmica. Começara a trabalhar cedo, aos catorze anos de idade, logo após a morte do pai. Via no esposo o oposto, pois, vindo de uma família que havia lhe dado de tudo, ele nada aproveitara. Ela tivera que abandonar a faculdade para cuidar da casa e trabalhar.

Beatriz sentia que Hebert era muito protegido pela mãe e por Marília, irmã mais nova (acima do P.I), as quais, com isso, dificultavam-lhe um possível processo de crescimento. Este padrão de relacionamento é visualizado no genograma com as linhas de superenvolvimento ligando estes membros familiares Ao mesmo tempo sentia uma certa manipulação da família do esposo sobre eles, muitas vezes justificada pela mesada dispensada a Hebert. Esta forma de expressar o afeto da família de origem sobre o novo casal é denominada por Stanton e Todd (1990) de primazia da família de origem sobre a família nuclear. $\mathrm{O}$ casal fica submetido às demandas da família de origem, que o impedem de desenvolver o subsistema conjugal de forma saudável.

Pudemos apontar, durante nosso trabalho, relações semelhantes de Beatriz e sua mãe com seu irmão drogadicto, apresentando-se assim o mesmo modelo funcional da mãe (Cerveny, 1994). Notamos quanto elas também o protegiam, maternando-o, como Marília e sua mãe faziam com Hebert.

Hebert ficava sempre irritado quando a esposa falava de sua ligação com o irmão. Parecia nutrir um sentimento de ciúme em relação a eles, sentindo-se excluído, e não compreendido por ela. Muitas vezes pareceu disputar com o cunhado a atenção de Beatriz, criando um conflito constante entre eles, demonstrado no genograma pela linha de conflito ligando estes três membros do sistema familiar. Por outro lado Beatriz também se sentia excluída pela família de Hebert. Ambos pareciam, cada um com sua história familiar, presos às suas famílias de origem, configurando lealdades familiares mantenedoras de padrões afetivos (Umbarger, 1983).

A relação de Beatriz com seu irmão adicto confirma os dados da literatura descritos por Mackensen e Cottone (1992), que referem a presença, na família de origem da esposa do drogadicto, de um irmão dependente químico muito próximo a ela.

Hebert parecia-se muito com seu pai, uma pessoa calada e séria, com traços depressivos. Não conseguia entender sua relação com a droga: "Não vejo nada de bom nela, nem ao menos me sinto bem sob seus efeito". Ao ser indagado, várias vezes, sobre os aspectos positivos que a droga lhe proporcionava, conseguiu, enfim, descrever como se sentia: "...alienado a tudo sem precisar resolver nada, sem o peso da obrigação familiar, me sinto vazio e livre".

Hebert parece tender ao pólo depressivo, como seu pai, procurando a droga para aliviar seu sofrimento, Kalina (1988), criando uma quase-mania, uma sensação de não ter obrigações com nada, libertando-se do peso familiar. O PI. repete o modelo paterno, que enfatiza o afeto incondicional pelos filhos, "meus filhos são a razão da minha vida...", manifestando uma lealdade intergeracional (com o pai), de acordo com Umbarger (1983).

Observamos também que Hebert se apresenta como delegado de ligação do pai, tendendo ao pólo depressivo: sob o efeitos da droga sente-se liberto do fardo familiar, vivendo o outro pólo, a mania: "vazio e livre". Era muito parecido com o pai, quando este usava álcool. Experimentava assim o "colorido da vida".

O PI. relata que os filhos, para ele, são as coisas mais preciosas que tem, mas não consegue mostrar-lhes o afeto que sente. Quando cobrado pela esposa sobre seu papel de pai, responde: "Se eu pudesse, deixaria as drogas por eles". O pai, senhor Mário, quando falou sobre sua abstinência de álcool, referiu sentir-se mais próximo de sua família, principalmente dos filhos. Apesar de sentir "a vida sem o colorido de antes", parece fortalecer-se ao mostrar a convicção de que "valeu o preço para ficar junto com a família".

Observamos que dona Terezinha, por ser mais formal e muito reservada, mesmo com o marido e os filhos, apresentava, de acordo com Stierlin e cols. (1986), a figura parental ordenada, enquanto o senhor Mário representava a figura parental desordenada. Na construção da relação conjugal parece haver uma complementaridade restritiva (C.R.): dona Terezinha, tendendo ao pólo depressivo, reprime, inibindo, o comportamento maníaco de senhor Mário, deixando-o mais adequado, porém mais depressivo "sem o colorido da vida". Esta falta de ajuste mútuo, com possibilidade de troca entre o casal a partir das diferenças que a complementaridade (sem ser restritiva) poderia promover, acaba por manter distante o relacionamento do casal, visualizado no genograma pela linha de distanciamento ligando os pais de Hebert.

Este padrão relacional também é encontrado no novo casal, Beatriz e Hebert. Quando procuramos investigar a relação conjugal das irmãs de Hebert, verificamos a presença de CR em Marília e seu esposo, enquanto na família nuclear de Magda, irmã mais velha do P.I, não pareceu haver CR.

A mãe, dona Terezinha, demonstrava ser superprotetora (Winnicot, 1996), mas não parecia 
ter consciência de suas condutas. Para ela, os filhos não cresceram: "sempre serão crianças para mim”. Pudemos ratificar essa sua postura perante seus filhos pelos relatos exagerados de controle de todos os membros da família. O seu papel professoral aparecia freqüentemente no cotidiano familiar, como também algumas vezes também nas sessões de terapia de família. Conotamos positivamente sua facilidade de ensinar, tendo-lhe mostrado que seus "alunos" já podiam caminhar com suas próprias pernas. Demonstrou-se muito resistente em reconhecer essa forma de relacionar-se com sua família. Era sempre muito ansiosa e evitava falar de sua dependência de benzodiazepínicos: "Foi o médico que me receitou”.

Foi possível perceber, várias vezes, o padrão adicto transgeracional da família (Umbarger, 1983), porém com defesas e acusações: “...mas doutor, a droga é um problema maior, incomparável”. Desta forma tentava minimizar o uso de álcool do esposo e o seu uso de calmantes. De acordo com Stanton e Todd (1990), é bastante significativa a incidência de indivíduos drogadictos cujos pais apresentam dependência de álcool ou de outras drogas lícitas.

Marília apontava o irmão, drogadicto, de Beatriz como a pessoa responsável por introduzir Hebert no mundo das drogas. Para ela, o problema vinha de fora de seu sistema familiar.

Percebemos que a família Flores funcionava como um sistema familiar emaranhado, de acordo com Minuchin e Fishman (1990), com fronteiras rígidas com o mundo externo, com dificuldade de aceitar novos integrantes, sentindo-se ameaçada com o que vem de fora do sistema familiar. Podemos observar como esta rigidez, muitas vezes, fragiliza o sistema familiar, deixando o mais vulnerável às drogas.

A ausência de Hebert em casa parece ter propiciado a intensidade de envolvimento de Beatriz com seus filhos, porém, de forma sistêmica. Tentamos analisar como essa situação se mantinha. De acordo com Macedo (1996), a família configurou-se numa triangulação patológica, com a função de diminuir a tensão entre o casal, provavelmente rompida com a chegada do segundo filho, cujas demandas desequilibraram o sistema, resultando no abuso de crack por parte do pai.

Trabalhamos os projetos e planos individuais de cada membro da família de origem e da nuclear. Os filhos foram vistos como metas de vida, constituindo-se como lema familiar "Os filhos são tudo em uma família". Provavelmente estavam sendo preparados para a função de realizar as expectativas destes. Nesse sentido, Hebert cobravase muito ao referir que seu pai largara a bebida pelos filhos, ao passo que ele, apesar de ter o mesmo objetivo, sentia-se fracassado em suas tentativas, não podendo assim cumprir sua função de delegado de ligação do pai. Usando como exemplo o curso de especialização que dona Terezinha estava fazendo, aproveitamos sua postura professoral para que ensinasse como se podia aprender a traçar planos individuais. Seu desejo de terminar sua especialização foi visto pela família como algo bom, a que ela própria poderia se dedicar mais.

Vimos a possibilidade de a família construir um novo lema familiar, que continuasse a valorizar os filhos, porém sem comprometimento da individuação de seus membros.

A valorização da autonomia dos membros familiares, com a possibilidade de criação de novas crenças e valores, sem a ameaça de rompimento com a família de origem, foi essencial para a autonomia do novo casal, dando a Beatriz e Hebert a oportunidade de entrarem em contato com as demandas de seu ciclo vital familiar. O casal pôde voltarse para seu subsistema conjugal e parental sem o peso do mito da família de origem.

O casal, adquirindo mais autonomia, pôde construir novos padrões de relacionamento, menos rígidos, que possibilitassem a realização pessoal sem detrimento da atenção familiar. Com a divisão de tarefas sem grandes cobranças, Hebert sentiu-se mais confiante em retomar a residência médica e manteve-se abstinente durante os meses em que saiu da clínica. A família nuclear continuou a terapia familiar mensal.

A questão da droga, que servia para flexibilizar o sistema familiar extenso, rígido, unindo os membros familiares, principalmente Dona Terezinha, Marília e Beatriz, para salvar Hebert (como um compromisso comum), não parecia mais necessária para que a família se reunisse. Surgiu assim um novo terreno relacional, menos tenso e mais acessível, para relações interpessoais.

\section{DESCRIÇÃO DAS CATEGORIAS DO MODELO ESTRUTURAL E ESTRATÉGICO}

Após a análise das dez sessões com a família Flores dentro dos moldes da terapia familiar modelo estrutural e estratégico, encontramos os seguintes resultados paras as categorias propostas pelos autores Minuchin e Fishman (1990) - estrutrual - e Haley (1979) - estratégica. 
Quadro 1. Resultado das Categorias de Acordo Com o Modelo Estratégico de Haley (1979) e Estrutural de Minuchin e Fishman (1990) (modelo E e E) Encontrados na Família Flores.

\begin{tabular}{|l|l|}
\hline \multicolumn{1}{|c|}{ Categorias do modelo E e E } & \multicolumn{1}{c|}{ Categorias do modelo E e E encontrado na família Flores } \\
\hline Fronteiras & Rígida, alternando com desligada sem seletividade de relações pessoais. \\
\hline Valores & Ligado à continuidade da família. Os filhos como realização do desejo dos pais. \\
\hline Mitos & Os filhos são tudo em uma família. \\
\hline Crenças & A força para vencer vem da dedicação e amor pela família. \\
\hline Lealdades & Lealdades transgeracionais PI com o pai e intrageracional; Beatriz com o irmão drogadicto. \\
\hline Padrão de interação & Superproteção representada por intensa aproximação, em seguida com distanciamento, caracterizando sequiências repetitivas de conduta. \\
\hline Limites e regras & Rígidos e incompatíveis, dificultando a formação do casal e uma nova família. \\
\hline Hierarquia & As mulheres detêm o poder, a mãe, na família de origem, com tendência a repetir o modelo na nova família. \\
\hline Coalizões e alianças & Coalizões e alianças alternando ao longo do ciclo da drogadicção. \\
\hline Triangulação & Aproximação mãe-bebê e pai distante e vulnerável às drogas. \\
\hline Padrão de Comunicação & Afetado pelas alianças e coalizões explícitas. \\
\hline Padrão afetivo & $\begin{array}{l}\text { Dificuldade de separação e individuação, com fixação na fase anterior do ciclo vital. PI adolescente e esposa com ligação com a família de } \\
\text { origem. Os irmãos parecem menos comprometidos, com melhor desenvolvimento individual e familiar. }\end{array}$ \\
\hline
\end{tabular}

Nos Quadros 2 e 3 se encontram as descrições das categorias propostas por Stierlin e cols. (1986) a partir de estudo com famílias com transtorno de humor e os dados por nós obtidos após análise das dez sessões de terapia familiar sistêmica com a família Flores, utilizando as categorias descritas por Stierlin e cols. (1986).

Quadro 2. Comparação Entre os Dois Tipos de Família: com Transtorno de Humor Estudada por Stierlin e cols. (1986), e com Farmacodependência - Família Flores - por nós Estudada.

\begin{tabular}{|c|c|c|}
\hline Categorias descritas por Stierlin e cols. & $\begin{array}{l}\text { Maníaco-depressivas, estudadas por } \\
\text { Stierlin e cols. }\end{array}$ & Farmacodependente por nós estudada \\
\hline $\begin{array}{l}\text { Construção/negociação da realidade } \\
\text { relacional Qualidade geral de } \\
\text { "flexibilidade" ou inflexibilidade" de } \\
\text { pressupostos, orientações e compromissos } \\
\text { básicos em comum }\end{array}$ & $\begin{array}{l}\text { A maior parte “inflexível”: duas construções } \\
\text { de realidades fixas ainda que mutuamente } \\
\text { exclusivas podem coexistir ou colidir entre si }\end{array}$ & $\begin{array}{l}\text { A maior parte do tempo dura, inflexível. Com a recaída } \\
\text { nas drogas o sistema se flexibiliza, aproximando os } \\
\text { membros para uma resolução em conjunto }\end{array}$ \\
\hline $\begin{array}{l}\text { Definições de relação/ clareza e } \\
\text { coerência } \\
\text { Nível em que os membros da família } \\
\text { concordam e se expressam claramente } \\
\text { (pública ou veladamente) em relação ao } \\
\text { tipo de relação que existe entre eles }\end{array}$ & $\begin{array}{l}\text { Definições de relações são normalmente } \\
\text { claras, ainda que limitadas a duas } \\
\text { alternativas rigidamente mantidas, que } \\
\text { podem se alternar ao longo do tempo }\end{array}$ & $\begin{array}{l}\text { Na abstinência de drogas, a comunicação é clara e repleta } \\
\text { de mútuas agressões; não se aceitam as diferenças. Na } \\
\text { recaída torna-se obscura, transparecendo geralmente uma } \\
\text { falsa colaboração mútua; os membros se unem para salvar } \\
\text { o PI. }\end{array}$ \\
\hline $\begin{array}{l}\text { Sistemas de valores/ ideologias familiares } \\
\text { Clareza e arraigamento dos valores que } \\
\text { orientam o comportamento dos membros }\end{array}$ & $\begin{array}{l}\text { Valores incompatíveis e inegociáveis } \\
\text { existindo lado a lado - "cisão" familiar }\end{array}$ & $\begin{array}{l}\text { Valores centrados na criação dos filhos em detrimento dos } \\
\text { objetivos pessoais. }\end{array}$ \\
\hline $\begin{array}{l}\text { Coalizões } \\
\text { Especialmente sua rigidez, afrouxamento e } \\
\text { visibilidade }\end{array}$ & $\begin{array}{l}\text { Membros da família pressionados a escolher } \\
\text { um lado, p. ex. a tomar partido de uma ou } \\
\text { outra maneira }\end{array}$ & $\begin{array}{l}\text { Coalizões claramente estabelecidas. A droga com função } \\
\text { de produzir um afrouxamento nas coalizões e } \\
\text { aparecimento de pseudo-alianças }\end{array}$ \\
\hline
\end{tabular}

Quadro 3. Conceitos de Stierlin e cols. (1986) Aplicados à Família com Farmacodependência - Família Flores.

\begin{tabular}{|l|l|}
\hline \multicolumn{1}{|c|}{ Conceitos de Stierlin e cols. (1986) } & \multicolumn{1}{|c|}{ Família Flores } \\
\hline Complementaridade restritiva & $\begin{array}{l}\text { Esposa com restrição ao esposo PI. , moldando suas condutas e } \\
\text { comportamento. }\end{array}$ \\
\hline Delegado de ligação & $\begin{array}{l}\text { PI. como delegado de ligação do pai, com lealdade transgeracional ligada à } \\
\text { dependência química. }\end{array}$ \\
\hline $\begin{array}{l}\text { Par ordenado (com traços depressivos) e par desordenado } \\
\text { (com traços maníacos) }\end{array}$ & $\begin{array}{l}\text { Esposa como par ordenado. "freando" os impulsos maníacos do esposo. PI. } \\
\text { par desordenado ( com traços geralmente depressivos) ciclando para traços } \\
\text { maníacos com o uso de drogas. }\end{array}$ \\
\hline
\end{tabular}




\section{CONCLUSÃO}

No decorrer de nosso trabalho, percebemos que as categorias e conceitos apresentados por Stierlin e cols. (1986) nos serviram grandemente não só para o aprofundamento dos nossos estudos sobre as interrelações pessoais do sistema familiar com membro farmacodependente, mas também para confirmar nossos pressupostos de que os padrões de depressão e mania presentes nos indivíduos drogadictos também se expressam no âmbito familiar. Tais padrões se retroalimentam no sistema familiar, estabelecendo padrões de conduta e comportamento repetitivos entre seus membros, que podem comprometê-lo, deixando-o mais vulnerável à drogadicção.

Essas categorias e conceitos relacional-descritivos levantados pela equipe de Heidelberg foram encontrados também fazendo parte da dinâmica da família por nós estudada nesta pesquisa, tais como: complementaridade restritiva, polarização entre par ordenado e par desordenado, as lealdades transgeracionais e invisíveis e alianças que vão configurar a postura de delegado de ligação dos membros familiares, principalmente o PI. Pudemos observar que, nas fases em que Hebert se apresentava como delegado de ligação de sua mãe (representante do pólo depressivo), ele demonstrava-se mais disponível para as mudanças orientadas pela terapia, assim como para as demandas de sua família nuclear. Nas fases opostas, como delegado de ligação do pai (geralmente representante do pólo de mania), Hebert tornava-se mais vulnerável à drogadicção, apresentando freqüentes recaídas no uso abusivo de drogas, e comportava-se como um adolescente, negligenciando seu papel de pai e esposo. Nessa fase, Beatriz, sua esposa, refere que se sentia como mãe de Hebert, que parecia disputar sua atenção com os filhos pequenos. Por outro lado, como podemos observar no mapa estrutural da família nuclear, Beatriz parecia sentir-se ameaçada com o movimento de Hebert para retornar à sua posição dentro do sistema familiar, configurando uma triangulação patológica: aproximação mãe-bebê e pai distante e mais vulnerável às drogas.

Notamos, também, a clareza do terreno relacional descrito por Stierlin e cols. (1986) com famílias com transtornos de humor, durante as sessões de terapia familiar, quando se oferecem ao terapeuta várias oportunidades de intervenção no sistema familiar. Se as famílias, por um lado, apresentam-se como um sistema rígido nas condutas, limites e regras, por outro lado, apresentam grande flexibilidade para lidar com os fracassos e a reorganização familiar ante as constantes crises do ciclo da drogadicção, assim como as famílias com membros com transtornos de humor estudadas pela equipe de Heidelberg. As crises vividas pela família em face do uso abusivo de drogas de Hebert pareciam funcionar como válvula de escape, da mesma forma como escreveram Stierlin e cols. (1986) em relação às crises de mania nas famílias com transtorno de humor. Outro paradoxo observado foram as distintas posições que o farmacodependente pôde assumir no desenvolvimento do processo da drogadicção, desde a de algoz da família até a de elo entre seus membros, colaborando para a construção de uma nova história familiar.

As famílias com dependentes de drogas por nós estudadas, assim como as com transtornos de humor de Heidelberg, são famílias em situação grave, muitas vezes de urgência clínica, necessitando de tratamento multi e interdisciplinar. A terapia familiar, em nossa pesquisa, assim como em outros trabalhos que utilizaram a terapia familiar para abordagem de outras patologias, mostrou-se extremamente útil, como catalisadora de um tratamento mais amplo e totalizador, conscientizando os membros familiares da importância de sua participação ativa no processo terapêutico e servindo também para melhorar os vínculos afetivos entre eles.

Acreditamos terem sido importantes neste trabalho as nossas considerações sobre a relação de comorbidade com transtornos de humor e farmacodependência no âmbito familiar, ampliando o estudo de Stierlin e cols. (1986), ao aplicar suas categoria às famílias com transtorno de humor, nos sistemas familiares com dependentes químicos. Em nosso entendimento, estamos oferecendo, com este trabalho, um novo olhar e uma maior compreensão da dinâmica do ciclo da adicção, acrescentando assim um caráter inédito à abordagem familiar do fenômeno da drogadicção. Acreditamos que estes padrões (de depressão e mania), anteriormente apenas relacionados com o paciente drogadicto, ao serem identificados como uma expressão de todo o sistema familiar se tornam fundamentais para o entendimento da dinâmica familiar desses sistemas com dependência química, sendo um fator importante na manutenção do ciclo da drogadicção.

A análise dos resultados e das informações por nós obtidos com este estudo serviu para melhor conduzir nosso trabalho com famílias mantidas sob o ciclo da drogadicção. Acreditamos que este tipo de abordagem aqui apresentado possa facilitar ao terapeuta e ao sistema familiar visualizarem as diferentes posições e responsabilidades que cada elemento assume dentro de sistema familiar, 
desfocando assim o papel do P.I. como algo estranho, incompreendido pelo sistema familiar. Consideramos também importante realizar maiores reflexões sobre o tema, a partir das considerações apresentadas, podendo assim ampliar as possibilidades de melhor prevenção e/ou tratamento do dependente e sua família.

\section{REFERÊNCIAS}

Bergami, N. B. B. \& Berthoud, C. M. E. (1997). A família em fase de aquisição. Em C. M. Cerveny \& C. M. E. Berthoud (Orgs.), Família e ciclo vital: nossa realidade em pesquisa (pp. 49-73). São Paulo: Casa do Psicólogo.

Bergeret, J. \& Leblanc, J. (1991). Toxicomanias: uma visão multidisciplinar. Porto Alegre: Artes Médicas.

Carter, B. \& McGoldrick, M. (1995). As mudanças no ciclo de vida familiar: uma estrutura para a terapia familiar. Porto Alegre: Artes Médicas.

Cerveny, C. M. O. (1994). A família como modelo descostruindo a patologia. São Paulo: Editorial Psy II.

Cerveny, C. M. O. (1996). Histórias familiares: conversando sobre mitos, crenças, segredos e profecias. Em D. Natrelli (Org.), Século XX e XXI: o que permanece e o que se transforma. (Vol.8, pp. 59-64). São Paulo: Lemos.

Cerveny, C. M. \& Berthoud, C. M. E. (1997). Família e ciclo vital: nossa realidade em pesquisa. São Paulo: Casa do Psicólogo.

Elkaïm, M. (1998). Panorama das Terapias Familiares. São Paulo: Summus.

Giami, A. (1989). Recherche en psychologie ou recherche clinique. En C.R. D'Allones (Org.), La démarche clinique em sciences humanies: Documents, méthodes, problémes (pp. 42-55). Paris: Bordas.

Haley, J. (1979). Psicoterapia familiar: um enfoque centrado no problema. Belo Horizonte: Interlivro.

Hoffman, L. (1987). Fundamentos de la terapia familiar: un marco conceptual para el cambio de Sistemas. Mexico: Fondo de Cultura Econômica.

Kalina, E. (1988). Drogadicção II. Rio de Janeiro: Francisco Alves.

Kaplan, H. I. \& Sadock, B. J. A. (1998). Compêndio de psiquiatria: ciências do comportamento e psiquiatria clínica. Porto Alegre: Artes Médicas.

Lourenço, J. S. (2001). O farmacodependente como elo para a coconstrução familiar. Dissertação de Mestrado Não-Publicada.
Programa de Pós-Graduação em Psicologia Clínica, Pontifícia Universidade Católica de São Paulo, São Paulo.

Lourenço, J. S. \& Cordás, A. T. (2006). Transtorno bipolar do humor. Em C. N. Abreu (Org.), Síndromes Psiquiátricas: diagnóstico e entrevista para profissionais de saúde mental. Porto Alegre: Artmed.

Macedo, R. M. S. (1996). Família e comunidade. Coletâneas da ANPEPP, 1(2), 8-10.

Mackensen, G. \& Cottone, R. (1992). Family structural issues and chemical dependency: A review of the literature from 1985 to 1991. The American Jouranl of Family Therapy, 20(3), 9-15.

Minuchin, S. (1992). Famílias funcionamento \& tratamento. Porto Alegre: Artes Médicas.

Minuchin, S. (1995). A cura da família: histórias de esperança e renovação contadas pela terapia familiar. Porto Alegre: Artes Médicas.

Minuchin, S. \& Fishman, C. S. (1990). Técnicas de Terapia Familiar. Porto Alegre: Artes Médicas.

Piszezman, M. L. R. M. (1999). Terapia familiar breve: uma nova abordagem terapêutica em instituições. São Paulo: Casa do Psicólogo.

Prefeitura do Município de São Paulo/ Secretária Municipal da Saúde (2004). Coordenação de Desenvolvimento da Gestão Descentralizada. Comitê de Ética em Pesquisa. Em Manual sobre ética em pesquisa com seres humanos (pp.14-18). São Paulo: PMSP

Silveira, D. X. (1997). Avaliação das propriedades psicométricas da escala de rastreamento populacional para depressão CES$D$ em população clínica e não clínica de adolescentes $e$ adultos jovens. Tese de Doutorado Não-Publicada, Programa de Pós-Graduação em Psiquiatria, Escola Paulista de Medicina, São Paulo.

Stanton, M. D. \& Todd, T. (1990). Terapia familiar del abuso y adccion a las drogas. Barcelona: Gedisa.

Stierlin, H., Weber, G., Schmidt, G. \& Simon, F. B. (1986). Features of families with major affective disorders. Family Process, 25(3), 325-336.

Umbarger, C. C. (1983). Terapia familiar estructural. Buenos Aires: Amorrortu.

Winnicot, D. W. (1996). Pensando sobre crianças. Porto Alegre: Artes Médicas.

Recebido em 30/09/2005 Aceito em 14/06/2006

Endereço para correspondência: Jair Lourenço Silva. Rua Arruda Alvim 107 - 32, Pinheiros, CEP: 05410-000, São Paulo-SP. E-mail: jalou@uol.com.br 